\title{
DESIGNING FUNCTIONAL CLOTHES FOR PERSONS WITH LOCOMOTOR DISABILITIES
}

\author{
Curteza Antonela ${ }^{1 *}$, Cretu Viorica1, Macovei Laura', Poboroniuc Marian² \\ ${ }^{1}$ Faculty of Textiles-Leather and Industrial Management, Technical University "Gheorghe Asachi" of lasi, \\ Dimitrie Mangeron Bvl. No.67, 700050, lasi, Romania \\ ${ }^{2}$ Faculty of Electrical Engineering, Energetic and Applied Informatics, Technical University "Gheorghe Asachi" of lasi, \\ Dimitrie Mangeron Bvl. No.67, 700050, lasi, Romania \\ *ACurteza@gmail.com, Tel. +0745537286
}

\begin{abstract}
:
The life quality improvement issue is a problem of national and international interest. This acquires total different values when it is to refer to a series of disadvantaged categories, that is the persons with locomotor disabilities. It is an inevitable social responsibility to create equal opportunities for disabled people, to prevent any intentional or unintentional discrimination that they face and apply positive discrimination if necessary to improve their living standards and to let them have an equal share from social development as productive individuals of society.

A disability is any kind of restriction or inability to accomplish a certain activity, which belongs to the interval considered as "normal" for a human being. Disabilities are characterized by deficiencies or excesses in the activity or behaviour that is normally expected from a person; they can be temporary or permanent, reversible or irreversible, progressive or regressive. The physical disabilities that require the use of wheelchairs imply the manufacturing of special clothing products that meet certain needs at a functional and/or therapeutic level.

The study presents the main aspects involved in designing and developing textile products for this category of users. Therefore, the apparel that is specially designed for persons with disabilities has to: allow more freedom and independence when is being worn, correspond to the aesthetic point of view, offer psychological benefits and help to socially integrate the individual who wears it. In addition, clothes should not hinder the individual's mobility and must allow the use of the chest and of the superior limbs to the maximum, they must be durable, have a low level of electrostatic charge, be absorbent and comfortable, present the so-called "rehabilitation functions", and last but not least, be beneficial for the wearer both from a physical and psychological point of view.
\end{abstract}

\section{Keywords:}

Disabilities, design, integration, functions, sensations, cool, heating, stitch

\section{Introduction}

Clothing plays an important role in our lives because it represents one of the basic physiological needs, which not only mirrors our status within the society but is also meant to provide comfort and protection against unwanted external factors. The perpetual transformations that the human body undergoes, as well as some other factors, tend to influence our preferences and behaviour regarding the clothing we wear. Clothing becomes even more important when we are dealing with senior or disabled citizens (the disability can be innate or acquired) because these people want to hide their physical imperfections and create a certain image of themselves in order to be able to establish relationships within society.

Throughout the years, several types of disability classifications have been elaborated, the most used being The International Classification of Functioning, Disability and Health [29], which establishes the following disability types: behavioural, communicational, personal care, locomotor, physical, dexterity, and situational disabilities.
Disability is the consequence of an impairment that may be physical, cognitive, mental, sensory, emotional, developmental, or various combinations of these. A disability may be present from birth or occur during a person's lifetime (From Wikipedia, the free encyclopaedia). Disabilities are an umbrella term, covering impairments, activity limitations, and participation restrictions. An impairment is a problem in body function or structure; an activity limitation is a difficulty encountered by an individual in executing a task or action; while a participation restriction is a problem experienced by an individual when confronted with life situations. Thus, disability is a complex phenomenon, reflecting an interaction between features of a person's body and features of the society in which he or she lives [6]. Individuals may also be qualified as disabled if they have had an impairment in the past or is seen as disabled based on a personal or group standard or norm. Such impairments may include physical, sensory, and cognitive or developmental disabilities. Mental disorders (also known as psychiatric or psychosocial disability) and various types of chronic disease may also qualify as disabilities. Some advocates object to describing certain conditions (notably deafness and autism) as "disabilities", arguing that it is more appropriate to consider them developmental differences that have been unfairly 
stigmatized by society $[14,24]$. However, other advocates argue that disability is a result of exclusion from mainstream society and not any inherent impairment $[15,28]$.

A physical disability is a limitation on a person's physical functioning, mobility, dexterity or stamina [21]. Other physical disabilities include impairments that limit other facets of daily living, such as respiratory disorders, blindness and epilepsy [20] (from Wikipedia, the free encyclopaedia). Physical disabilities can occur on a short term (a fractured joint) or on a long term (e.g. paraplegia). Some medical cases of disability can improve in time, whereas others cannot be cured or ameliorated. Depending on each case, the disability can be contained by administrating medication or through therapy sessions, but not if the patient was born with it. Disabilities have a strong impact on one's ability to move around freely. The functional capacities that are hindered by motor affections are: walking, climbing the stairs, sitting or standing for a long period of time, grabbing or handling various objects, maintaining body balance and coordination, lifting, stretching, as well as other ordinary activities [17, 25]. Almost all patients who were the victims of an accident or of a vascular/cerebral trauma develop a physical condition that limits or impairs their ability to eat, get dressed, take care of themselves, transfer or move.

\section{Designing clothes for disabled people}

The design of these kinds of functional textiles and clothes goes beyond the well-known conventional boundaries while intertwining with other domains, such as medicine, biotechnology, nanotechnology, physics, computing, so as to meet the complex and multifaceted requirements of the users, the disabled people [9]. Clothing for special needs represents a class of functional clothing that is developed to improve the quality of life of disabled people (and not only) whose body shape, size, mobility and dexterity are significantly different from that of the so-called "normal people". Reported studies have shown that these groups are very sensitive to the clothing they wear and to their overall personal appearance. The needs of these persons are distinctive and different and thus there is a need for designing clothing specifically engineered to their requirements. Thus, the design consideration has to include, among others, changed body shapes, mobility limitations, psychological and social needs. [9, 16]

Throughout the years, many studies that were conducted resulted in the elaboration of clothing articles that were customized so as to address the characteristics, manifestations and the impact of several types of disabilities on the lives of the ones who are affected [23]. Many of the disabled people live under the permanent stress of having no choice but to acquire clothes from regular stores. Usually, such retail facilities do not provide services and products that would meet the needs of disabled customers. This is why clothing designers and manufacturers are considering the creation of adequate articles from an ergonomic and aesthetic point of view, which would fit this particular category of customers, according to the principles of universal design. Universal design (or inclusive design) refers to broad-spectrum ideas meant to produce buildings, products and environments that are inherently accessible to older people, people without disabilities and people with disabilities (from Wikipedia, the free encyclopaedia). To provide psycho-emotional comfort for disabled people, it has been suggested that the creation of products that are in line with the requirements are part of the so-called "universal fashion" and, at the same time, can be worn by everyone (including the people who suffer from loco-motor disabilities).

The life quality of disabled people can be ameliorated by improving the design and functionality of clothes. Unlike the majority of the population, the specific needs of disabled people vary according to certain requirements that are triggered by a particular necessity. Thus, clothing must provide additional comfort at functional and sensory levels, as well as at a psychological one. The textile products that are created for disabled individuals end up being far more expensive than their regular counterparts because their dimensions and design do not correspond to those of the standard products created for people who do not suffer from disabilities. On top of everything, these special textile products must have special functions and be manufactured by using fabrics with special properties, such as:

- certain tactile properties, especially when the product addresses people with sensitive skin;

- thermal comfort, which becomes paramount for people in wheelchairs or for those who spend a lot of time in bed [1, 22]; - be able to remove humidity created through the process of perspiration (one of the most widespread problems), which implies optimal humidity absorption and air circulation [8].

When designing clothes for disabled people, researchers focus on satisfying the needs at a social, physical and psychological level. Therefore, a number of aspects have to be taken into account, such as: style, colour and design, and the fabrics that will be used. The design of clothing for disabled people entails the integration of a variety of components that are synthesized in Figure 1. The functional textile products have to be developed according to:

- the requirements of the design process and of the concept "design for all", on all aesthetic aspects;

- the functions imposed by these atypical bodies;

- the demands required by the life environment and by the activities specific to people with disabilities.

The clothing specially designed for disabled people must allow more freedom and independence when being worn, but it also has to be fashionable. This is why it is essential that these products be comfortable, appealing to the eye, trendy, easy to put on/take off, accessible to all those who are disabled, safe and able to adapt to the wearer's physical needs. This particular type of clothing must satisfy the following requirements:

- to provide freedom of movement;

- be able to keep the handicap under control;

- to provide the required level of safety and comfort;

- to provide the necessary moral and psychological comfort ;

- be easy to maintain and cleaned in the washing machine like regular laundry, high resistance to rumpling and easy recovery from folding;

- to assure adequate thermal isolation through the use of 
appropriate fabrics, without increasing the volume and weight of the product;

- to assure the minimum required level of body odour retention by using natural fibres and/or applying anti-bacterial treatments or antibacterial finishing.

The main requirements for the products that are made for disabled people in wheelchairs are as follows:
- an average volume to fit the available wheelchair space;

- elastic fibres might be used so as to assure superior comfort; - adequate closure systems (zippers, Velcro strips, buttons, snaps) must be used so as to facilitate the handling of such clothes;

- the clothing must be long lasting, absorbent and comfortable to wear;

- the clothing must have a low electrostatic charging level and be easy to maintain.

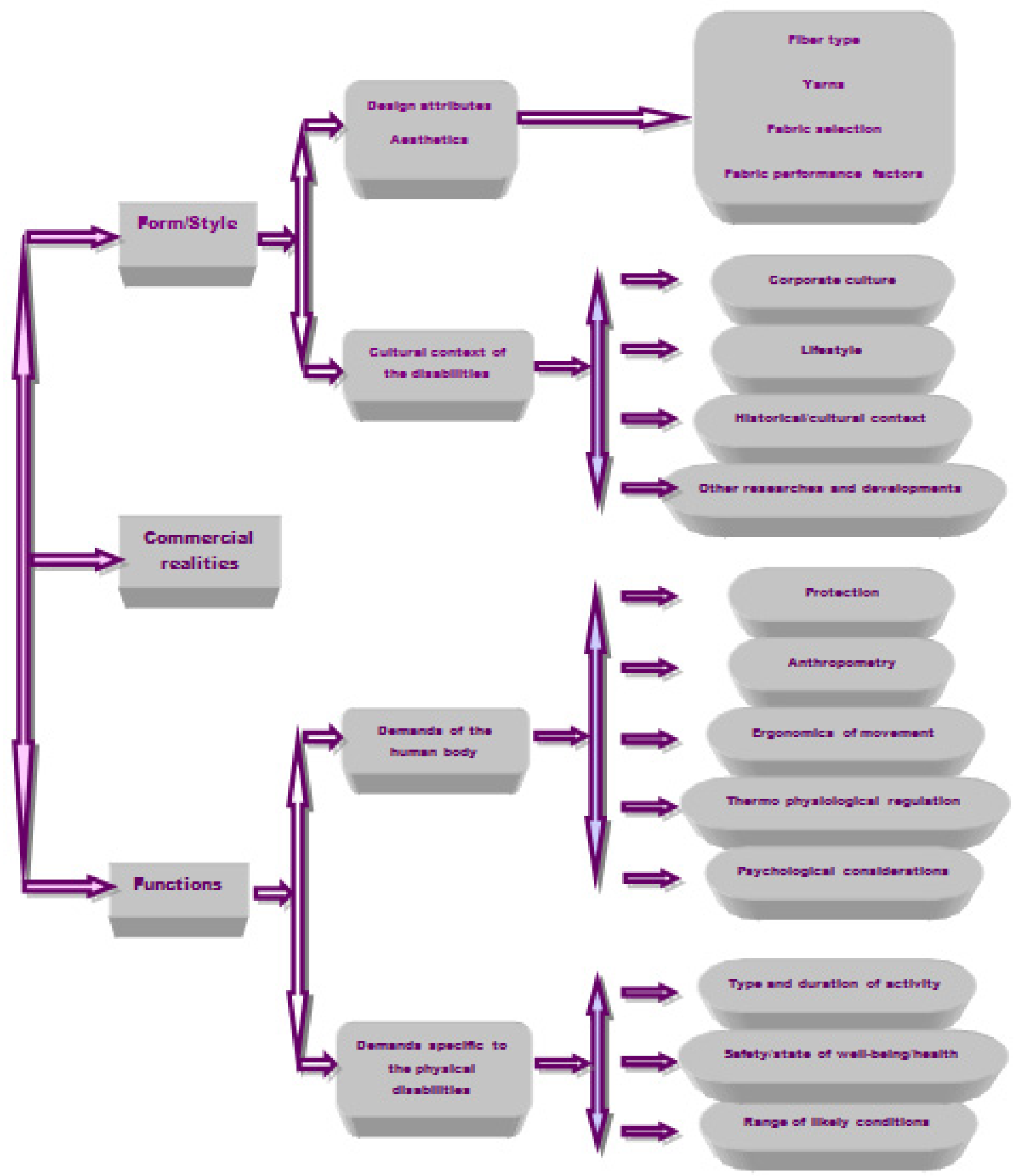

Figure 1. The main components integrated in the design process of the clothes for disabled people. 
Between the people with physical disabilities and non-disabled people, there are evident differences in the living states. Due to physical differences people with physical disabilities may have psychological characteristics distinct from normal people. Therefore, people with limb disabilities have special needs for the aesthetic and functional structures of clothing, distinct from non-disabled people, and consequently their garments have specific design requirements. Appearance without aesthetic consideration may seriously compromise their sense of selfrespect; therefore, we must take into full consideration their special physiological comfort and psychological tolerance. [3]

Certain clarifications are also necessary regarding the terminology, the definitions and the differences between barrier-free design, universal design and assistive technology. Barrier-free design is what it is used to call the issue of access. It is predominantly a disability-focused movement. Universal design broadly defines the user. It is a consumer market-driven issue. Its focus is not specifically on people with disabilities, but all people. The assistive technology is the personal use devices, those things focused on the individual and that compensate or help one function with a disability (an example of assistive technology is the wheelchair) [7].

\section{Specific functions imposed by the cool}

\section{sensation}

When a person's body movement is considerably hindered on long periods of time (e.g. the people who use wheelchairs), several modifications occur at a physical level which lead to a lower muscular activity and therefore to the occurrence of atrophy, poor metabolism and bone demineralization. The general modifications mentioned above are accompanied by dysfunctions that affect most of the body organs and systems, systematically described in Table 1.

From the wide range of locomotor physical disabilities, this study focuses on the ones that occur at the level of the inferior limbs and require the use of wheelchairs. The affections that lead to such disabilities are mainly hemiplegia and paraplegia. [18]:
- Hemiplegia occurs when half of the body loses voluntary motility.

- Paraplegia occurs when the lower limbs are paralysed, the clinical sign being a motor deficit (the complete disappearance or the diminishing of the lower limbs muscular force).

Considering the above-mentioned disabilities, the goal of the researchers is to create clothing that meets the functional and recovery needs of the clients that suffer from motor dysfunctions requiring the use of wheelchairs. Even when people with disabilities do report about what "it is like" to have their impairments, those reports may vary considerably. The most obvious reason is that there is tremendous variation in the sensory, physical and functional states of which "impaired" or "disabled" people are capable. [12]

Poor blood circulation and lower skin temperature of the body parts of people with disabilities, such as the residual limbs of amputees and the feet of poliomyelitis patients, tend to weaken the muscle functions and lead to muscular atrophy. To compensate for the impairment of the affected body parts, the unaffected body parts are forced to endure more pressure and accomplish more functions, and so are usually endowed with more powerful muscles and more flexible joints. For example, people with lower limb disability often have healthier and stronger upper limbs and people with upper limb disability more flexible and powerful lower limbs. [3]

At rest, the body produces heat at a rate of approximately $70 \mathrm{~W}$, or $1 \mathrm{kcal} / \mathrm{min}$, whereas the rate may be $2100 \mathrm{~W}$ (30 kcal/min) during maximal exercise in well-trained athletes. In the case of people who have spinal cord injuries ( $\mathrm{SCl}$ ), three of the four factors necessary for regulating temperature are affected (Binkhorst, 1995; Hopman, 1993, 1994). Specifically, circulating blood volume, sweat production and skin surface area for effective heat transfer to the environment are affected. The extent to which the circulation is affected depends on the level and severity (incomplete or complete) of the spinal cord lesion. At rest, the temperatures of the skin (Ts) covering the torsos and legs of the able bodied subjects in the Hopman (1994) study were similar $\left(35^{\circ} \mathrm{C}\right)$, indicating an even distribution of blood flow to the skin in all regions of the body. In contrast, in the case of all subjects with $\mathrm{SCl}$, the temperature of the legs

Table 1. Dysfunctions occurring as a result of diminished muscular activity.

\begin{tabular}{|c|c|c|c|}
\hline $\begin{array}{c}\text { 1) At the level of the } \\
\text { muscular system }\end{array}$ & $\begin{array}{c}\text { 2) At the level of the } \\
\text { osteoarticular system }\end{array}$ & $\begin{array}{c}\text { 3) At the level of the } \\
\text { cardiovascular system }\end{array}$ & $\begin{array}{c}\text { 4) At the level of the } \\
\text { respiratory system }\end{array}$ \\
\hline $\begin{array}{c}\text { Muscular hipotrophy } \\
\text { Muscular contracture } \\
\text { Musculotendinous } \\
\text { retraction. }\end{array}$ & $\begin{array}{c}\text { Bone demineralisation } \\
\text { Pains } \\
\text { Joint erosions }\end{array}$ & $\begin{array}{c}\text { Redistribution of blood } \\
\text { Orthostatic hypotension } \\
\text { oedema } \\
\text { Thrombosis }\end{array}$ & Fluid stasis \\
\hline $\begin{array}{c}\text { 5) At the level of the } \\
\text { digestive system }\end{array}$ & 6) At the level of the urinary \\
system & $\begin{array}{c}\text { 7) Preserving the integrity of } \\
\text { the tegument }\end{array}$ & \\
\hline $\begin{array}{c}\text { Crucial modifications } \\
\text { Underfeeding } \\
\text { Nutrition dystrophy } \\
\text { Undernourishment }\end{array}$ & The difficult evacuation of \\
urine & Compressions \\
Pressure ulcer & \\
\hline
\end{tabular}


$\left(32^{\circ} \mathrm{C}\right.$ ) was about $4^{\circ} \mathrm{C}$ lower than that of the upper body (near $36^{\circ} \mathrm{C}$ ), indicating an impaired skin blood flow below the lesion [11]; the patients report feeling cold in that particular area [27].

\section{Textile heating structures}

Considering that, as it was stated earlier in our paper, one of the issues with which people in wheelchairs are confronted is the sensation of cold [19] even if the environmental temperature is not considerably low, part of our researches focused on the development of a number of textile products that have an additional heating function. In doing so, we also took into account the accomplishments reported at an international level $[2,4,5,10,13,26,30]$. The process relied on the use of electro conductive yarns that can be bought on the market which were incorporated into elastic stitches on various textile supports. In the following part of our paper, we will present the results of tests carried out by using an electro conductive yarn DA5393 made of $30 \mathrm{~mm} \mathrm{(22 \% )} \mathrm{stainless} \mathrm{steel} \mathrm{fibres} \mathrm{covered}$ by polyester fibres $167 / 96 \times 1 \mathrm{dtex}(78 \%)$, and three versions of samples to which elastic stitches that incorporate the conductive yarn were applied. The elastic stitches were done by using an Überdeck sewing machine. The conductive yarn was inserted through the thread gripping device. The selection of the textile supports that were used for applying the technology of integrating the conductive yarns through sewing was done by considering the following factors: the product's destination, the raw materials that were used, the type of machine and the processing technique. The selected samples are:

$\mathrm{V}_{1}$ - double-layered weft-knitted fabric; $100 \%$ PES back and front side and the connected thread made from nylon; thickness $3.69 \mathrm{~mm}$.

$\mathrm{V}_{2}-$ single jersey, $100 \% \mathrm{Bbc}$, thickness $0.92 \mathrm{~mm}$.

$V_{3}$ - relief jacquard, front side PA and back side PES, thickness $1.58 \mathrm{~mm}$.

The conductive yarn was connected to an electric power supply and the resulting temperature of the fabric was measured with an infrared thermographic camera. The main idea was to design the electrical resistance of the yarn, and of the corresponding stitch, in such a way that it can be operated with a low-voltage battery in order to obtain a wearable system. The laboratory test bench has been configured so as to perform measurement on conductive yarns as well as on textile structures embedding these conductive yarns. It consists of: a power supply $\left(U_{\max }=40 \mathrm{~V}\right.$, $I_{\max }=5 A$ ), AC\&DC multimeter (voltage, resistance, etc.) and an infrared thermographic camera Fluke Ti125. The infrared thermographic camera was placed approximately $50 \mathrm{~cm}$ away from the heated samples and the examinations were carried out at $20 \pm 2^{\circ} \mathrm{C}$. All textile products radiate infrared energy. The quantity of energy is based on the actual surface temperature and the surface emissivity of the product. Many common objects and materials such as wood, water, skin and cloth are very good at radiating energy and it is easy to get relatively accurate measurements. For surfaces with high emissivity, the emissivity factor is considered to be up to $90 \%$. Sometimes, the adjustment to the emissivity setting will allow the thermal imager to calculate a more accurate estimate of the actual temperature; the emissivity factor has been adjusted to 0.95 .

The first tests have been performed on the DA5393 conductive yarn, because no data related to its heating properties were available (see Figure 2).

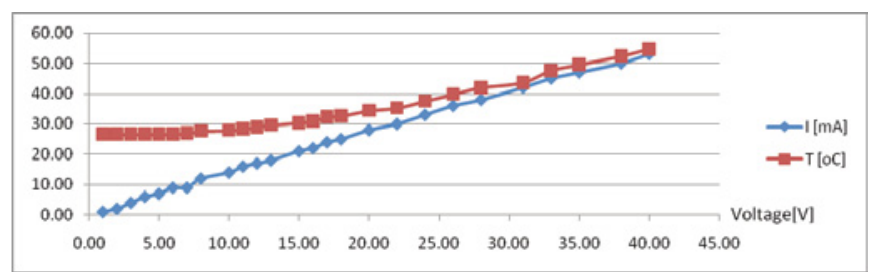

Figure 2. The diagrams of current intensity and temperature against applied voltage for the DA5393 conductive yarn (90-cm length; electrical resistance $R=744 \Omega$ ).

Basically, an $1 \mathrm{~m}$ length of DA5393 conductive yarn will require an applied voltage of around $28.88 \mathrm{~V}$ in order to make the yarn reach a temperature of $40^{\circ} \mathrm{C}$, which corresponds to an electric intensity of approximately $36 \mathrm{~mA}$.

The results of the experiments in the case of the three selected samples are presented in the following figures: Sample V1 Figures 3-5; Sample V2 - Figures 6-8; Sample V3 - Figures 9-11.

Basically, one would need a power of about $0.661 \mathrm{~W}$ per $1 \mathrm{~m}$ length of DA5393 conductive yarn to reach a temperature of $40^{\circ} \mathrm{C}$; only two rows of seams were connected to receive power in parallel.

To obtain a temperature of $40^{\circ} \mathrm{C}$, the adequate levels of applied voltage and current intensity, respectively, according to the results presented in Figures 3-11, are presented in Table 2. The electric intensity $(\mathrm{I})$ values are the ones required to generate a temperature of $40^{\circ} \mathrm{C}$, regardless of the length of the conductive yarn used to accomplish the stitching.

Table 2. The electric tension and electric intensity measurements for the analysed samples.

\begin{tabular}{|c|c|c|c|}
\hline Sample & $\mathbf{I}(\mathbf{m A})$ & $\mathbf{U}(\mathbf{V})$ & $\begin{array}{c}\text { Electrical resistivity of the } \\
\text { conductive yarn for a stitch } \\
\text { of } \mathbf{1 2 . 5} \mathbf{~ c m}\end{array}$ \\
\hline $\mathrm{V}_{1}$ & 34 & 17.5 & $1026 \mathrm{k} \Omega /$ row \\
\hline $\mathrm{V}_{2}$ & 21 & 16.2 & $765 \Omega /$ row \\
\hline $\mathrm{V}_{3}$ & 18 & 14.8 & $650 \Omega /$ row \\
\hline
\end{tabular}

The assessment of the obtained results shows that the version with the best heating potential is $V_{3}$, which also entails the lowest battery consumption. The viable solutions must require as few batteries as possible and therefore the lowest possible voltage, maintaining at the same time the adequate electric 

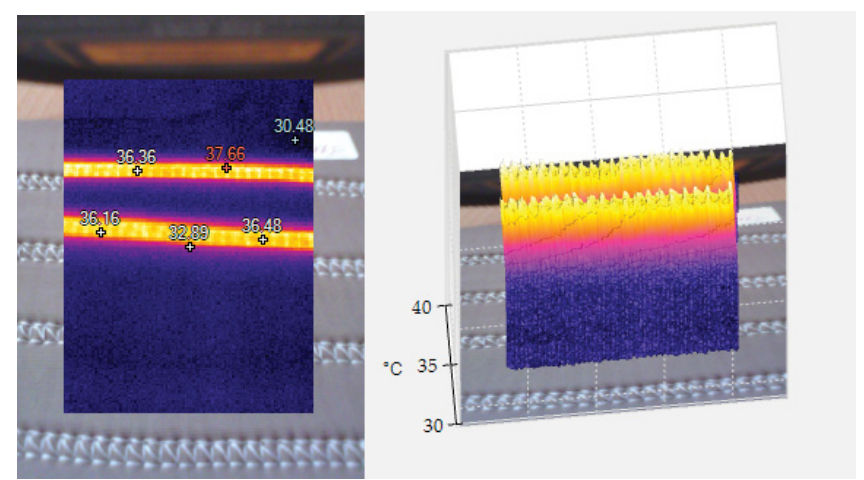

Figure 3. Images taken during the tests for sample V1.

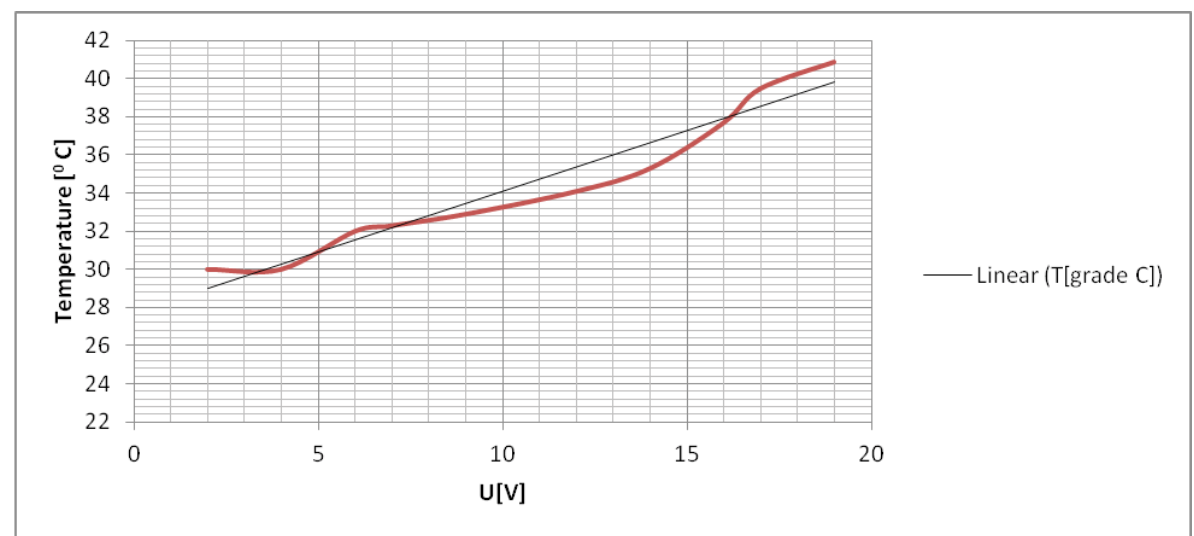

Figure 4. A graphical representation of the temperature - applied voltage function, sample $\mathrm{V}_{1}$.

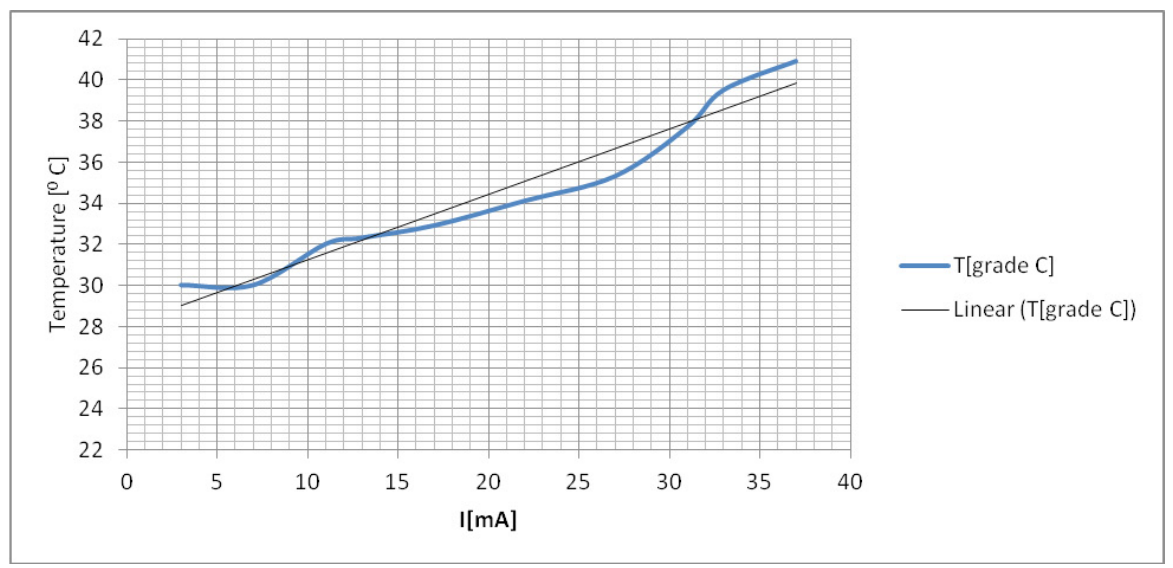

Figure 5. A graphical representation of the temperature - current intensity, sample $\mathrm{V}_{1}$.
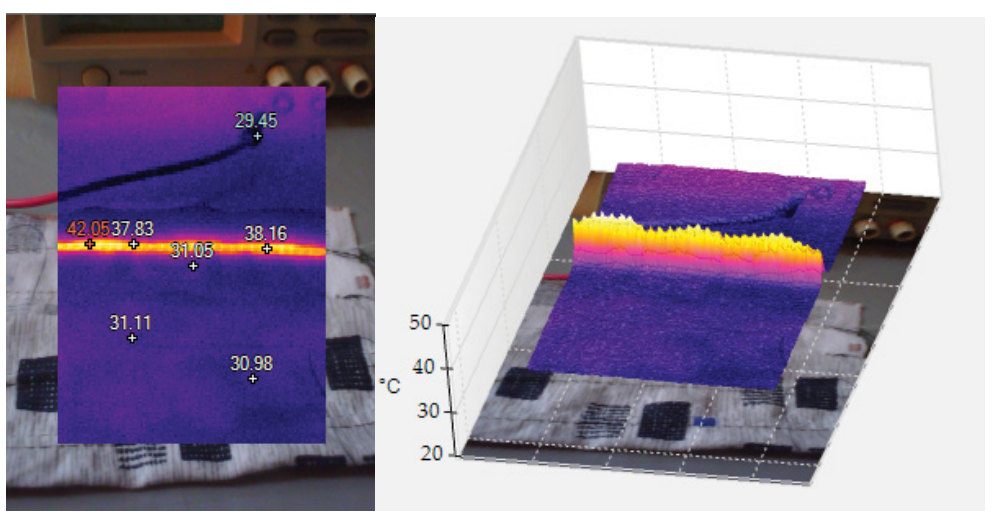

Figure 6. Images taken during the testing of the sample $\mathrm{V}_{2}$. 


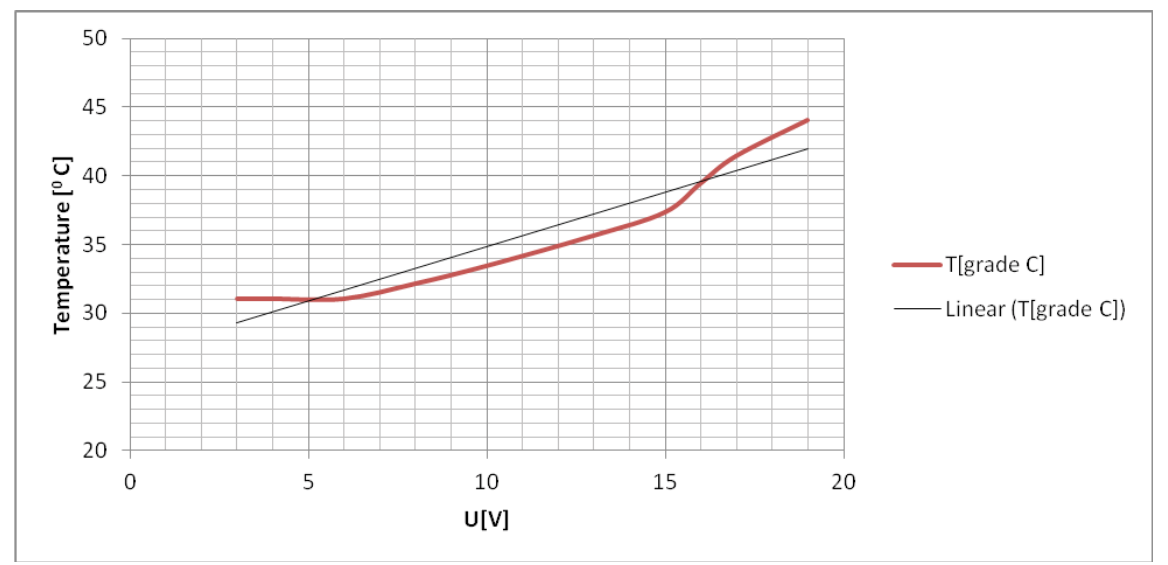

Figure 7. The temperature-applied voltage function for sample $V_{2}$.

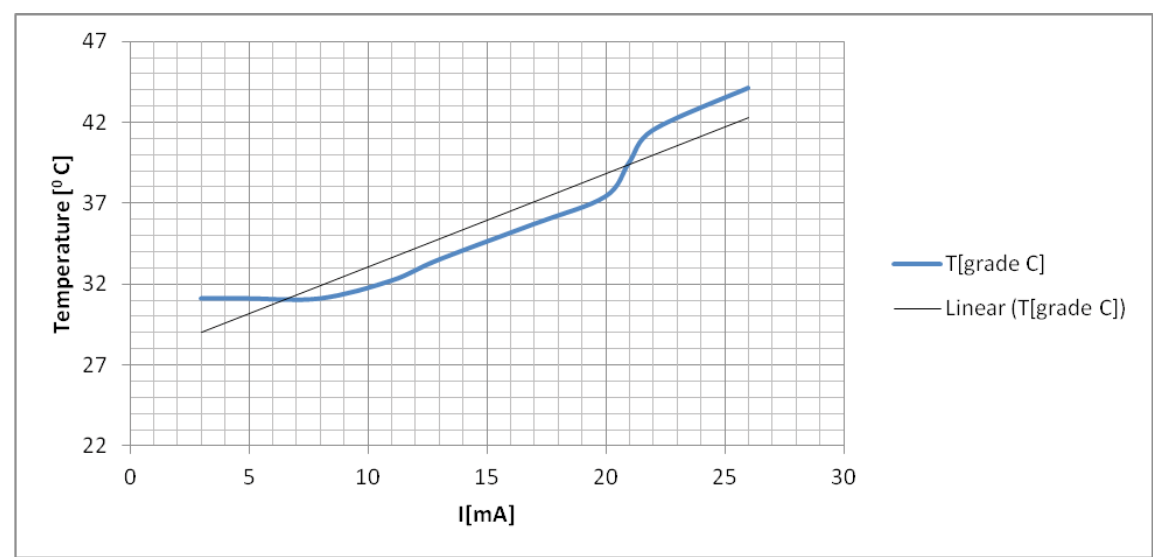

Figure 8. The temperature-current intensity function, sample $\mathrm{V}_{2}$.
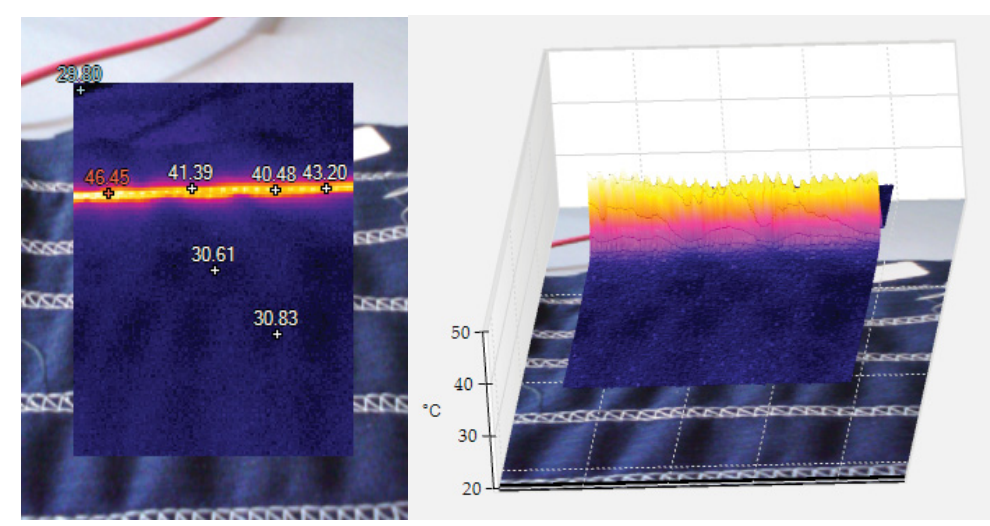

Figure 9. Images taken during the testing of sample $V_{3}$.

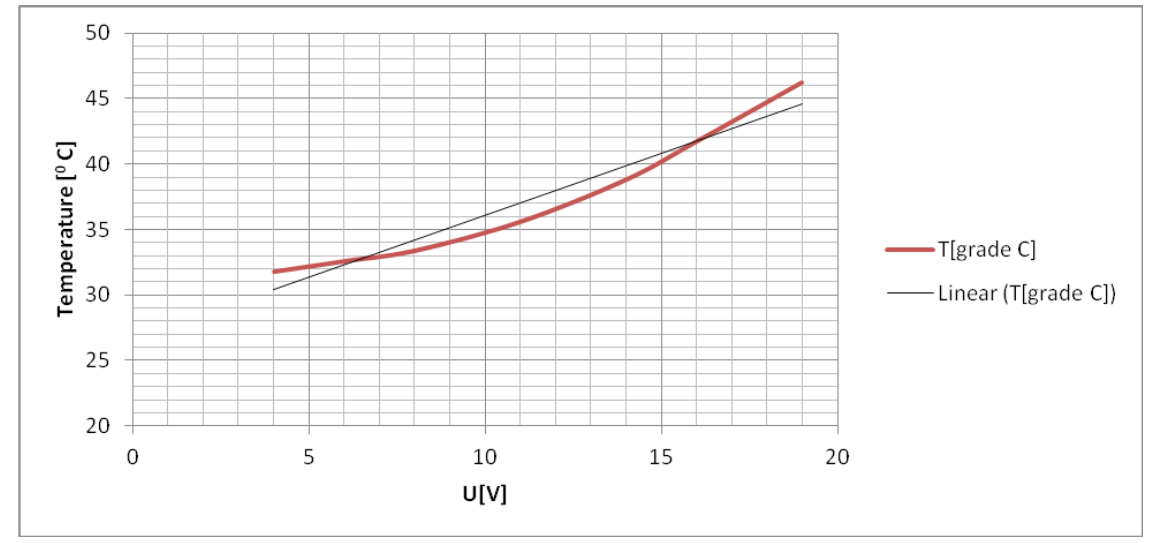

Figure 10. The temperature-applied voltage function, sample $V_{3}$. 


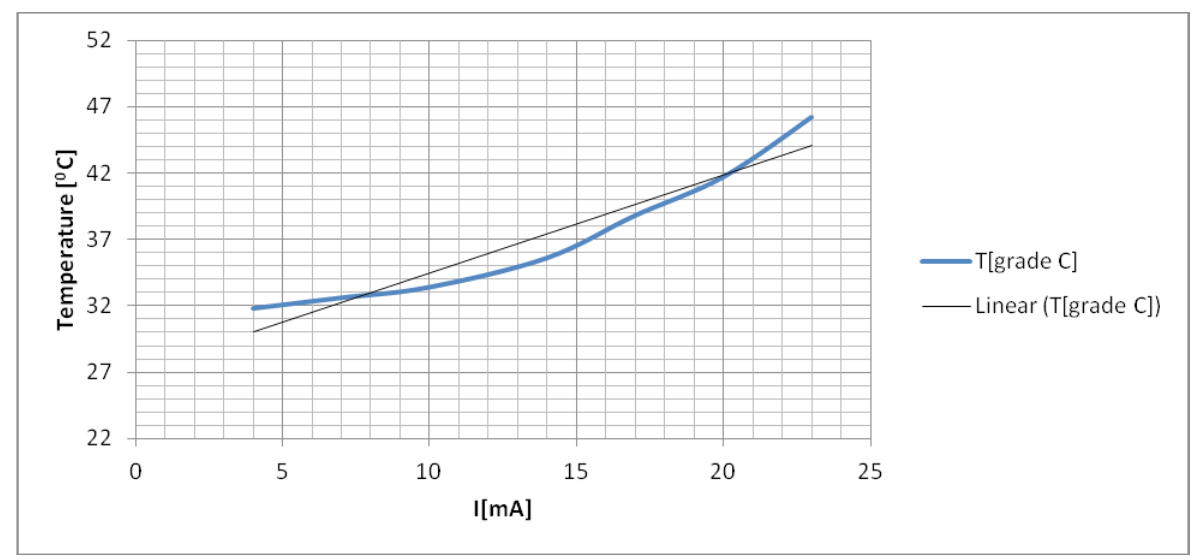

Figure 11. The temperature-current intensity function, sample $V_{3}$.

power necessary to reach the needed temperature, $40^{\circ} \mathrm{C}$ in this case.

\section{Conclusions}

The process of designing apparel products for persons who suffer from locomotory disabilities and who use the wheelchair aims at:

- A general direction that channels on manufacturing clothes that meet the requirements of such special textile products in a manner that focuses on the particular needs of the persons wearing them and by achieving superior standards (from the point of view of utility, functionality, comfort and aesthetics).

- A specific direction that refers to the requirements imposed by the health state of the customers, in this case the persons with locomotor disabilities; the apparel products can contribute to the therapeutic activities of improving and even curing some locomotor deficiencies, also presenting additional functions such as heating.

To meet the special requirements of people with disabilities, for different types of clothes might be used fabrics with special properties, capacities and functions, such as: antibacterial, proper humidity management, water proof, wear and cleaning resistant, non-flammable, warmth retention or heating. The optimized structure of the textile/clothing assembly can guarantee the needed functions, protect the body and make the person feel more comfortable.

Despite their physical difference, people with disabilities need and want to gain a sense of social identity and acceptance just like any other person, and their requirement for aesthetically pleasing clothing may be stronger. Their special needs for clothing design are critical to their quality of life and, at the same time, to their individuality in fashion. [15]

\section{ACKNOWLEDGEMENTS}

The presented results were financially supported by the EU \& Romanian UEFISCDI in the framework of the Eureka Programme, under the Project ProTexHeatINT, grant no. 317E/23.08.2012.

\section{References}

[1] Amrit, U. R. (2007). Bedding Textiles and Their Influence on Thermal Comfort and Sleep, AUTEX Research Journal, Vol. 8, No.4, December 2007 (C) AUTEX, pp. 252-254.

[2] **** Beckert, G. (2013). Interview: warmX heatable textiles, Apolda, http://www.groz-beckert.com accessed 7 August 2014.

[3] Chang, W. M., Zhao, Y. Z., Guo, R. P., Wang, Q., Gu, X. D. (2009). Design and Study of Clothing Structure for People with Limb Disabilities, Journal of Fiber Bioengineering and Informatics, Vol. 2, No.2, pp. 61-66.

[4] De Angelis. (2001). Heated garment. U.S.A. Patent No: 2001/0047.992. http://www.patentbuddy.com/ Patent/20010047992, accessed 15 August 2014.

[5] Dias, T., et al. (2008). Development of Electrically Active Textiles. Advances in Science and Technology, Vol. 60, pages 74-84.

[6] Disabilities. World Health Organization. Retrieved 11 August (2012). http://www.who.int/topics/disabilities/en/ accessed 7 August 2014.

[7] Disability: Definitions, Models, Experience, Stanford Encyclopaedia of Philosophy, First published (2011). http:// plato.stanford.edu/entries/disability/ accessed 13 August 2014.

[8] Dutkiewicz, Jacek K. (2006). Cellulosic Fiber for Odor and PH Control, AUTEX Research Journal, Vol. 6, No 2, June 2006 ( ) AUTEX, 91-101, 91-101.

[9] Gupa, D. (2011). Functional clothing - Definition and classification, Indian Journal of Fibre \& Textile Research, Vol. 36, December 2011, pp. 321-326.

[10] Harlin, A., Ferenets, M. (2006). Intelligent textiles and clothing. Introduction to conductive materials. Ed.: $\mathrm{H}$. R. Mattila, Cambridge, England: Woodhead Publishing Limited, CRC Press, ISBN-10:1-84569-162-8, page 218.

[11] Hopman, Maria T.E., Binkhorst, Rob A. (1997). Sports Science, Spinal Cord Injury and Exercise in the Heat, SSE\#66-Volume 10, Number 3, http://www.gssiweb.org/ Article/sse-66-spinal-cord-injury-and-exercise-in-the-heat accessed 13 August 2014.

[12] International Classification of Functioning, Disability and Health (ICF), Geneva: World Health Organization. (2001). http://whqlibdoc. who.int/publications/2001/9241545429. pdf accessed 15 August 2014.

[13] Kochman, E. et al.: Textile heater with continuous 
temperature sensing and hot spot detection. (2004). U.S.A. Patent no. 6713733 B2. http://www.google.com/patents/ US6713733 accessed 15 August 2014.

[14] Ladd, P. (2003). Understanding Dear Culture: In Search of Deafhood. Multilingual Matters. p. 502. ISBN 1-85359545-4.

[15] Langtree, I. (2014). Definitions of the Models of Disability. Disabled World. Retrieved July 24, 2014, http://www. disabled-world.com/definitions/disability-models.php, accessed 7 August 2014.

[16] Mace, Ronald L. (1998). A Perspective on Universal Design, Excerpt of a presentation, FAIA, at "Designing for the 21st Century: An International Conference on Universal Design," June 19, 1998, Hofstra University, Hempstead, New York, Title and text Edited by Jan Reagan for publication, http://www.ncsu.edu/ncsu/design/ cud/about_us/usronmacespeech.htm accessed 13 August 2014.

[17]Metts, R. (2000). Disability Issues, Trends and Recommendations for The World Bank, 2.

[18] Neurological diseases. (2012). http://www.netmedic.ro/ boli-neurologice/ accessed 7 August 2014

[19] Petcu, I. (2012). Researches regarding textile products development for people with physical disabilities. PhD theses. Technical University "Gheorghe Asachi" of lasi, Romania.

[20] Physical Disabilities, California State University, Northridge, accessed 7 August 2014.

[21] Physical disability - Key facts on physical disability. (2012). http://pubsites.uws.edu.au/ndco/employment/what/ physical.htm, accessed 7 August 2014.

[22] Rehim, Zeinab S. Abdel., Saad, M. M., Shakanker, M. El.,
Hanafy, I. (2006). Textile Fabrics as Thermal Insulators, AUTEX Research Journal, Vol. 6, No 3, September 2006 (C) AUTEX, 148-161.

[23] Shaari, N., Suleiman, N. (2009). Assistive Clothing for Disable People based on Kansei Approach Using Indigenous Clothing Construction, http://www.iasdr2009. org//Papers/ accessed 7 August 2014.

[24] Solomon, A. (2008). The New Wave of Autism Rights Activists. New York Magazine. http://nymag.com/news/ features/47225/ accessed 7 August 2014.

[25] Steinfeld, E., Maisel, J., Feathers, D., D’Souz, C. (2010). Anthropometry and Standards for Wheeled Mobility: An International Comparison, Assistive Technology: The Official Journal of RESNA, Volume 22, Issue 1, Special Issue: Space Requirements for Wheeled Mobility, 51-67.

[26] ${ }^{* * * *}$ Textile heating elements prevent loss of patient body heat. Hohenstein Institutes. (2011). http:// specialtyfabricsreview.com/articles/051911_textile_ heating.html accessed 15 August 2014.

[27] Weiss, T. C. (2013). Hypothermia (Cold Stress) - Symptoms, Treatment and Prevention. http://www.disabled-world. com/medical/first-aid/cold-stress.php accessed 13 August 2014.

[28] Welcome to the Autistic Community! Autistic Self Advocacy Network. Retrieved July 24, 2014, http://autisticadvocacy. org/wp-content/uploads/2014/02/WTTAC-AdolescentFINAL-2.pdf accessed 7 August 2014.

[29] World Health Organization, International Classification of Impairments, Disabilities and Handicap (ICIDH), Page last reviewed: June 19, 2013, Content source: CDC/National Center for Health Statistics, http://www.cdc.gov/nchs/about/ otheract/icd9/icfhome.htm accessed 15 August 2014.

[30] Zhang, H., Xiaoming, T., Tongxi, Y. (2006). Conductive knitted fabric as large-strain gauge under high temperature. Sensors and Actuators A, Vol.126, pages 129-140. 